\title{
Multifunctional, Catalytic Nanowire Membranes and the Membrane-Based 3D Devices
}

Wenjun Dong, Andrew Cogbill, Tierui Zhang, Samrat Ghosh, Z. Ryan Tian*

Chemistry and Biochemistry, University of Arkansas, Fayetteville, AR 72701, USA

Supporting information:

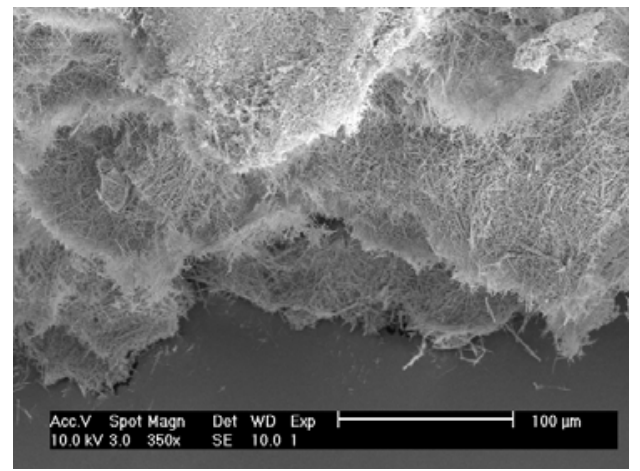

S1. A low-resolution FESEM photograph indicating the multi-deck texture calcined at $700{ }^{\circ} \mathrm{C}$.

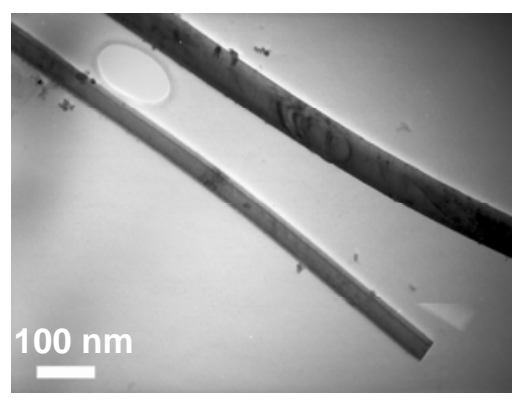

S2. A TEM picture presenting the single nanowire diameter for the sample calcined at $700{ }^{\circ} \mathrm{C}$. 


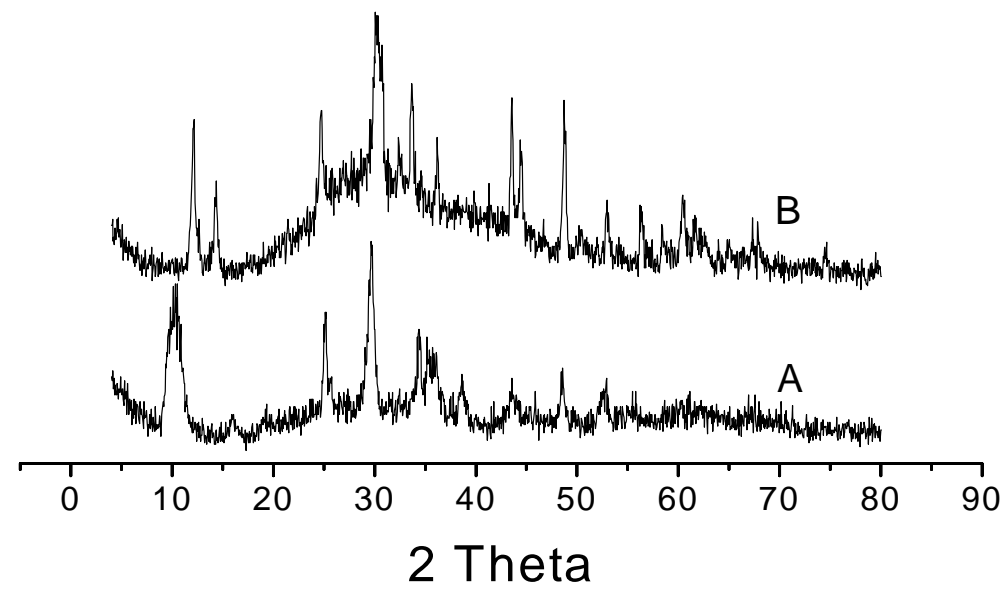

S3. X-ray powder diffraction pattern of titanate nanofiber. (a) as prepapred. (b) calcined at $700{ }^{\circ} \mathrm{C}$ for $3 \mathrm{~h}$. 